\title{
O CONCEITO DE POLÍTICO EM SCHMITT COMO UMA FORMA DE DOIS LADOS: A LÓGICA DA IDENTIDADE E A EXCLUSÃO DO OUTRO POR MEIO DA COMUNICAÇÃO SUBVERSIVA
}

\author{
David Denner de Lima Braga ${ }^{1}$ \\ Selmar José Maia²
}

\begin{abstract}
Resumo: O trabalho objetiva fazer uma leitura do conceito político de Carl Schmitt e relacioná-lo com a noção de ordens jurídicas autocráticas, argumentando que se trata de uma noção incompatível com a ordem democrática, a partir do conceito de forma de George Spencer Brown. Assim, trabalha-se o conceito do político a partir da distinção amigo-inimigo, e que compartilha os pressupostos sociológicos da diferenciação funcional da sociedade. Por fim, busca-se alternativas no conceito de Heil, de desintegração amistosa, dando um sentido que permita ter maior largura para alcançar não apenas os imigrantes, mas os grupos diversos que disputam espaços de poder.
\end{abstract}

Palavras-chave: Teorias dos Sistemas; Carl Schmitt; Forma amigo-inimigo; Diferença; Indiferença.

\section{THE CONCEPT OF THE POLITICAL IN SCHMITT AS A TWO-SIDED FORM: THE LOGIC OF IDENTITY AND THE EXCLUSION OF THE OTHER THROUGH SUBVERSIVE COMMUNICATION}

\begin{abstract}
The present work aims to study Schmitt's concept of the political and connect it with the notion of autocratic legal orders. Departing from the concept of form by SpencerBrown we argue that Schmitt's notion isn't aligned with the democratic order. Thus, we study the concept of the political starting with the distinction friend-enemy, which shares the sociological bases of functional differentiation of the world society. In conclusion, we try to find alternatives in the Heil's concept of convivial disintegration, seeking a sense broaden enough to reach not only immigrants, but each group disputing spaces of power.
\end{abstract}

Key words: Systems Theoriy; Carl Schmitt; Friend-enemy form; Difference; Indifference.

\footnotetext{
${ }^{1}$ Doutorando em Direito Público do Programa de Pós-Graduação em Direito da Universidade do Vale do Rio dos Sinos (Unisinos) e Mestre em Direito em Constitucionalismo e Democracia pela Faculdade de Direito do Sul de Minas (FDSM). E-mail: daviddlbraga@yahoo.com.br

2 Doutorando e Mestre em Direito Público pela Universidade do Vale do Rio dos Sinos - UNISINOS. Especialista em Direito Civil e Direito Empresarial pela Faculdade Damásio Educacional de São Paulo. Graduado em Direito pelo Centro Universitário da Serra Gaúcha - FSG. Bolsista do Programa de Aperfeiçoamento de Pessoal de Nível Superior - CAPES. Advogado Empresarial e fundador do Escritório Maia Advocacia Corporativa. Contato: selmar@maiaadvocaciacorporativa.com.br.
} 


\section{INTRODUÇÃO}

O presente trabalho parte do pressuposto de que existem sistemas sociais diferenciados dentre os quais o Direito e a Política, cada um com o seu código próprio, mas ligados por uma constituição. Adota-se uma posição a partir da teoria dos sistemas sociais autopoiéticos e isso implica entre outras coisas, aceitar que a sociedade mundial é formada de comunicação e especificamente reconhecer que embora Direito e Política sejam sistemas distintos, há nexos estreitos e evidentes que tornam ambos os sistemas muito próximos (LUHMANN, 2003, p. 291). Direito e Política são sistemas fechados que compõem cada qual a seu turno o ambiente um do outro, cuja relação se faz através do conceito de acoplamento estrutural, que se caracteriza por uma relação mais estável, do que a que ocorre com acoplamentos operativos. Essa relação estável entre o Direito e a Política é dada pela constituição.

A despeito, portanto, de serem sistemas distintos e operativamente fechados não se pode negar que irritações recíprocas existem entre o Direito e a Política. São fechados no nível operacional, mas abertos no nível cognitivo. A teoria de Luhmann assinala ao Direito o código operacional direito-não direito, e à política o código governo-oposição.

A teoria de Schmitt também faz uso de uma codificação para definir o político que é a codificação amigo-inimigo. Cuida-se de uma forma, no sentido de Spencer Brown, que retrata uma distinção compatível com a época em que o texto foi escrito, em 1932, mas que é mais antiga que a forma governo-oposição, e é incompatível com uma ordem jurídica, que como a brasileira, se pretende pluralista e democrática.

Nesse estudo se argumenta a respeito da tensão que existe quando uma ordem jurídica democrática passa a conviver com um sistema político que deixa de operar no campo do código governo-oposição para atuar com o código amigo-inimigo. Como dito, Direito e Política estão muito próximos, estabilizados pelo acoplamento estrutural que é constituição. Sugere-se que a forma amigo-inimigo compromete a ordem democrática e ameaça Direitos fundamentais. O poder tende a estabelecer espaços autárquicos e a acolhida de novas demandas desestabiliza os interesses dos grupos incluídos (RODRIGUEZ, 2019).

Essa tensão faz parte da composição da democracia e é difícil imaginar uma situação real onde ela seja eliminada. A distinção de Rodriguez (2019) entre zonas democráticas e zonas de autarquia permite, além da leitura analítica dos movimentos políticos e sociais, enquadrar o conceito de Carl Schmitt de político, ou seja, daquele que decide pela 
diferenciação amigo-inimigo, dentro de uma concepção de direito autárquica, no sentido de antidemocrática e avessa às diferenças. Faz sentido, então, falar em toxic turn, nos tempos negros que presenciam essas duas décadas iniciais do séc. XXI.

Atualmente, inclusive durante a Pandemia do Covid, pôde ser observado, por exemplo nas democracias americana e brasileira, um recrudescimento do discurso que resgata, mesmo sem o saber, a divisão do mundo schmittiana entre amigo-inimigo. A estratégia de Trump, principalmente durante as eleições, de atacar a China e conseguir apoio popular, utilizando-se da lógica do "nós contra eles", bem como a construção do muro na fronteira do México, e aqui no Brasil, para não alongar os exemplos, a fala do Ministro das Relações Exteriores, denominando o vírus de Comunavírus, ou vírus chinês, ilustram a decisão política de definir inimigos no plano externo. Além disso, os ataques dos presidentes americano e brasileiro à imprensa definem no plano interno o inimigo a ser combatido.

Não se trata em nenhum desses casos de uma definição política com base no código luhmanniano governo-oposição, trata-se do código schmittiano amigo-inimigo.

As consequências do descompasso entre Política e Direito são instabilidade política e desgovernabilidade, agravadas pelo contexto da crise sanitária. No caso brasileiro, aparece ainda um constante apelo às forças armadas como instância decisória da (des)continuidade democrática. Esse apelo ficou bastante evidente nas mobilizações do dia 07 de setembro de 2021, quando houve pedidos de intervenção militar e ataques às instituições democráticas.

Desde a promulgação da Constituição de 1988 (CF/88) com o fim da ditadura militar foi alterada a relação da sociedade brasileira com suas instituições democráticas, de maneira que o direito não é meramente um instrumento para o exercício poder que possa ser utilizado para atacar as instituições (RODRIGUEZ, 2009). Nesse sentido, muito embora não tenha havido relato de violência ou depredações do patrimônio público as manifestações de 7 de setembro podem ser interpretadas como um retrocesso institucional ao período anterior a outubro de 1988, porque demandam uma intervenção militar que parte do pressuposto de que as instituições democráticas atrapalham o desenvolvimento do País, num claro movimento autoritário e populista, que já se apresentou em vários outros países e momentos históricos, como no caso da Itália de Mussolini.

De mais a mais, nas faixas dos manifestantes (em português e inglês, numa clara tentativa de transnacionalização das reivindicações) e, também, nos discursos do Presidente Jair Bolsonaro foi gerado um ruído antidemocrático, que não se coaduna com a harmonia 
entre os três poderes, pois contém uma ameaça de disruptura institucional com o Poder Judiciário, através de pedidos de impeachment dos Ministros do Supremo Tribunal Federal (STF) no Senado Federal.

No mesmo sentido, nesses protestos, também se presenciou um ruído no sentido do descumprimento das decisões normativas do STF, como aquelas proferidas pelo Ministro Alexandre de Moraes para tentar conter atividades de desinformação da população mediante fake news.

Do ponto de vista da teoria dos sistemas, Rocha (2013a, p.35) ao comentar a teoria luhmanniana, destaca que a comunicação é elemento primordial da sociedade conectada em rede e nesse sentido, para Luhmann, a comunicação é uma síntese entre a informação, o ato de comunicação e a compreensão. Isto é, ao observarmos o discurso que aparece nas mobilizações do dia 7 de setembro é possível concluir que existe um descompasso entre esses três elementos pilares da comunicação (informação, comunicação e compreensão) posto que, se de um lado, a comunicação referente a manifestações públicas e pacíficas têm proteção constitucional, de outro, a comunicação autoritária e antidemocrática não tem.

Portanto, a priori, observa-se que o discurso apresenta-se como democrático na roupagem, na medida em que afirma estar contido dentro da liberdade constitucional de expressão, todavia, subverte a compreensão da própria comunicação quando ataca as instituições democráticas que lhes asseguram a manifestação ao requerer intervenção militar, fazer apologia ao AI-5, exigir o fechamento do STF, e atacar a legitimidade da urna eletrônica para as eleições presidenciais de 2022, com a exigência do voto impresso e auditável.

Essa posição política entrechoca-se com o ordenamento jurídico democrático e esse descompasso precisa ser resolvido ou com a ordem democrática se convertendo em autarquia ou com a readequação dos movimentos políticos ao ordenamento democrático.

Essa teoria política, portanto, é refratária, avessa às diferenças. Pressupõe certa homogeneidade das pessoas, um conceito de povo e de nação, que não se adequam com a sociedade complexa e multicultural do Séc. XXI, nem mesmo com a evolução do Direito em direção ao pluralismo jurídico, que é uma realidade. Nesse sentido, a forma inimigo ${ }^{3}$ trabalha

\footnotetext{
${ }^{3}$ Poderia ser usada a expressão invertida, inimigo-amigo, para destacar a partir de qual lado se iniciam as operações, seguindo o cálculo das formas de Spencer Brown, ou mesmo apenas usar a expressão a forma inimigo, subtendido que haverá um valor reflexivo, evidente no contexto do presente texto, que é o outro lado, "amigo".
} 
na lógica da identidade, mas não na lógica da diferença, conforme verificar-se-á no decorrer da presente pesquisa.

Ao revisitar a distinção schmittiana de maneira crítica, o presente trabalho tenta demonstrar que mesmo uma teoria antidemocrática, que não dá conta da multinormatividade e complexidade do mundo atual e que pressupõe a lógica da identidade pode ser atual para a descrição de vários aspectos que compõem o espaço político mundial de modo geral e o brasileiro em específico. Serve para alertar ao risco da criação de zonas de autarquia e da corrosão da forma de Direito democrático.

Por fim, em aportes finais, demonstrar-se-á que existe um caráter polêmico de todos os conceitos políticos (SCHMITT, 2020). Por mais que a teoria de Schmitt possa causar aversão não se pode negar que a partir dela muitas reflexões são possíveis, as quais permitem aumentar o entendimento e a compreensão a respeito do estado de coisas atual.

\section{O CONCEITO DE POLÍTICO}

Uma nota interessante do texto de Schmitt é a maneira como ele perpassa de maneira transversal dois temas fundamentais da teoria dos sistemas: a questão da diferenciação funcional e o assinalamento de um único código ao sistema funcionalmente diferenciado da política.

Com respeito à diferenciação funcional precisa ficar claro que, na fase pré-moderna, havia um amálgama da política e da moral religiosa no topo da pirâmide social, ou seja, uma estrutura política de dominação (diferenciada em superior e inferior) somada a uma semântica moral-religiosa (NEVES, 2009). As observações de Neves ressaltam que a Constituição é condição de possibilidade e de asseguramento da distinção entre as esferas política e jurídica. Quando há a vontade de predominância do sistema político sobre os demais sistemas, a exemplo do jurídico, arrisca-se a dizer que se está próximo da "morte da democracia".

Aliás, sobre o conceito de morte de democracia oportunas são as contribuições de Levistky e Ziblatt (2018, p.11) no aclamado livro Como as democracias morrem, ao destacarem que "estamos atravessando desde 2013 um momento turbulento e que nos faz ter a sensação de que algo está fora da ordem em nossa democracia”. Eles sustentam também em sua pesquisa que "o processo de subversão das democracias muitas vezes começa com palavras", isto é, nas palavras dos autores, "demagogos atacam seus críticos com termos 
ásperos e provocativos - como inimigos, subversivos e até mesmo terroristas" (LEVITSKY; ZIBLATT, 2018, p. 79), algo muito próximo com o discurso presidencial do dia 7 de setembro de 2021.

Entretanto, como ressaltado por Rocha (2009, p20), no contexto da diferenciação funcional:

\begin{abstract}
Um sistema diferenciado deve ser, simultaneamente, operativamente fechado, para manter a sua unidade, e cognitivamente aberto, para poder observar a sua diferença constitutiva. Portanto, a sociedade possui como elemento principal a comunicação: a capacidade de repetir as suas operações, diferenciando-se das suas observações. A tomada de decisões produz tempo dentro da sociedade. Nesta perspectiva, não é o consenso que possui o sentido das decisões, mas a diferenciação.
\end{abstract}

Com isso se pode destacar que malgrado a política de um lado e o direito do outro sejam sistemas operativamente fechados, no sentido de que realizam suas operações internamente ao mesmo tempo em que delimitam suas fronteiras, eles são cognitivamente abertos ao que ocorre no seu ambiente, dentro do qual existem outros sistemas.

Rocha prossegue (2009, p. 23(explicando que:

\begin{abstract}
As organizações são as estruturas burocráticas encarregadas de tomar decisões coletivas a partir da programação e do código dos sentidos. Os sistemas adquirem a sua identidade numa permanente diferenciação com o ambiente e com os outros sistemas, graças as decisões das organizações. O Poder Judiciário pode ser visto como uma organização voltada à consecução das decisões do sistema do direito. A produção do diferente em cada processo de tomada de decisões gera o tempo. Quando a diferenciação ocorre numa metaobservação do sistema, surgem paradoxos que constituem a efetiva matriz da história.
\end{abstract}

Relevante o papel das organizações, sobretudo as de envergadura política para a sociedade. Um embate entre as instituições, Poder Judiciário e Poder Executivo tende a forçar um desequilíbrio das forças, mediante a tentativa de se alcançar o primado de um sistema sobre o outro. Assume-se nesse trabalho que o primado sistêmico ameaça a própria diferenciação funcional, com possibilidade de retorno àquele amálgama referido anteriormente, onde as decisões são tomadas com bases alheias ao sistema em questão. Por exemplo, decidir politicamente com base no sistema religioso, o que levaria de um Estado 
laico a um Estado confessional, ou decidir juridicamente mediante o código amigo-inimigo, o que corromperia o código do sistema jurídico.

Sugere-se que o modo como a política na sociedade mundial tem se comportado nos últimos anos, com um backlash contra o multiculturalismo e o toxic turn, pode ser descrito com acurácia a partir do modelo schmittiano.

Propõe-se, portanto, a leitura de Schmitt a partir de um referencial sistêmico, com ênfase na parte analítica da teoria dos sistemas, que é o cálculo das formas de Spencer Brown (1972). Segundo esse autor, quando um espaço é recortado (severed) ou separado (taken apart) nasce um mundo (BROWN, 1972, p. v). A distinção entre dois lados, uma vez realizada, permite que se faça a indicação de um dos lados (e não do outro lado). O mundo político que Schmitt cria parte da distinção amigo-inimigo, que compõe uma forma, composta de um valor indicado e de um valor reflexivo. Sustenta-se que o lado de onde parte a composição schmittiana é o lado "inimigo", assumindo o outro lado, "amigo", valor meramente reflexivo. É preciso buscar entender as implicações disso e como ele chegou até esse critério.

Na mesma esteira, esses conceitos de amigo-inimigo, ou "nós contra eles", também podem ser identificados na obra de Thornhill (2021, p. 305):

\begin{abstract}
Muito claramente, o populismo convida os membros individuais da sociedade a se unirem em torno de novas coletividades políticas, definidas, não por uma representação equilibrada, mas por seu compromisso com seu compartilhamento da ação soberana. O foco no exercício da soberania tem permitido, frequentemente, aos partidos populistas incitar determinados grupos sociais dos sistemas nacionais de inclusão, e a mobilizá-los de maneira enfaticamente solidária, muitas vezes acentuando a oposição a outros grupos políticos. É por esta razão que o populismo frequentemente concebe "a vontade do povo" em termos nacionalistas em oposição aos grupos de minorias, e como um rechaço vingativo da proteção às minorias baseadas em direitos individuais. Conforme mencionado, a tendência nacionalista não é universal entre os populistas, e não há uma convergência necessária entre populismo e nacionalismo. Em alguns casos, governos que podem ser caracterizados como populistas são apoiados por comunidades de minorias, e projetaram uma concepção de povo soberano que abrange grupos étnicos múltiplos. Um exemplo importante disso é encontrado na história recente da Bolívia, com Evo Morales. Na maioria dos casos, porém, o apoio populista é sustentado pela capacidade dos partidos políticos de projetar identidades nacionais ligados a sentimentos antiminorias. Isto fica claro na retórica discriminatória usada contra migrantes e minorias no Brasil, nos EUA, na Polônia, no Reino Unido e na Hungria.
\end{abstract}

Com base nesse autor afirma-se que o caso das mobilizações de 7 de setembro de 2021 apresentam os traços característicos de governos populistas onde os ataques às instituições 
democráticas e a necessidade de combater inimigos, muitas vezes invisíveis, legitimam um embate para assegurar a unidade da "nação", que surge como conceito para forçar a hegemonia dos grupos de situação, da suposta maioria, sobre demais grupos minoritários, mediante a política "nós versus eles".

De outra parte, no âmbito de sua teoria dos sistemas, Luhmann também buscou encontrar um código binário para o poder, meio de comunicação simbolicamente generalizado do sistema político da sociedade. Ele buscou avançar a teoria de Parsons com respeito aos meios de comunicação, especialmente o Poder, ao ligá-la com o conceito de diferenciação social (LUHMANN, 2017, p. 120) ${ }^{4}$. Nesse passo a distinção ensaiada para a codificação do sistema político foi progressista/conservador. Mais tarde, em trabalho posteriores já se encontra a formulação governo/oposição (LUHMANN, 1989).

Quando critica o equívoco de equiparar o político ao estatal, em busca de um critério de definição do político (SCHMITT, 2020, p. 46), o autor é categórico em dizer que não existem assuntos neutrais, ou seja, apenas sociais ou apenas estatais. Nada é neutro no sentido de não ser político ou não ser estatal. Com isso se consegue eliminar a referência ao Estado como possível critério. Não é o fato de uma questão ser estatal ou deixar de sê-lo que fará dela uma questão política, e nisso assiste razão ao autor. Ao mesmo tempo a referência que ele tem aos demais sistemas sociais (SCHMITT, 2020, p. 47), religioso como contraposto ao político, cultural, econômico, jurídico, científico como contraposto ao político dão sinais de que uma das bases de onde parte sua teoria é a diferenciação funcional da sociedade moderna.

Isso fica ainda mais claro, quando Schmitt afirma que (2020, p. 49-50):

Daí que o político se tenha de encontrar em diferenciações últimas que lhe são próprias, às quais se pode reconduzir todo o agir político em sentido específico. Assumamos que, no âmbito do moral, as diferenciações últimas são bom e mau; no estético, belo e feio; no econômico, útil e nocivo, ou, por exemplo rentável e não rentável

Essa percepção, que é crucial para a teoria dos sistemas elaborada por Luhmann, de assinalar a cada sistema social um código binário, permite fazer uma leitura de Schmitt, que a adapte aos elementos da teoria dos sistemas autopoiéticos, ao mesmo tempo em que confere

\footnotetext{
${ }^{4}$ No prefácio da reedição inglesa do livro, Michael King esclarece que "publicado em 1975, o texto alemão sobre Macht (Poder) representa a culminação de enormes esforços. O livro pode ser visto como a primeira aplicação da recentemente desenvolvida, ou em desenvolvimento, teoria dos meios de comunicação simbolicamente generalizados". Ele destaca também que nesse momento Luhmann ainda não havia iniciado a fase autopoiética. Tradução nossa. Cf. (LUHMANN, 2017, p. XIV).
} 
ao texto uma nota de atualidade. Schmitt consegue ser preciso em estabelecer logo de início o procedimento que vai utilizar para encontrar "o" critério de distinção do político, como ele mesmo diz, "uma diferenciação particular, [...] independente [...] autônoma e, enquanto tal, elucidativa sem mais enquanto critério simples do político" (SCHMITT, 2020, p. 50). O resultado é a famosa distinção amigo-inimigo, que é complementada com o seguinte esclarecimento, fundamental para o desenvolvimento do item subsequente (SCHMITT, 2020, p. 51 e 52$)$ :

O inimigo político não precisa de ser moralmente mau, não precisa de ser esteticamente feio; não tem de surgir como concorrente econômico e até talvez possa parecer vantajoso fazer negócios com ele. Ele é precisamente o outro, o estrangeiro, e é suficiente, para a sua essência, que ele seja existencialmente, num sentido particularmente intensivo, algo outro e estrangeiro [...].

Com essa explicação o autor busca destacar como o critério do político difere e é independente dos critérios das demais esferas diferenciadas da sociedade. Mas ao mesmo tempo ele produz algo significativo e que aparece explícito no texto: a exclusão do outro, a exclusão do estrangeiro ${ }^{5}$.

Koselleck (2020, p. 312 e ss.) ao tratar dos conceitos (e contraconceitos) de inimigo alerta que todas as esferas da vida dos seres humanos conhecem um aqui e um ali, um lado de cá e de lá, mas que certo limiar é ultrapassado quando se conceitua o outro, o estrangeiro, como inimigo. Nesse caso se abre uma trilha sangrenta. Ele destaca três limiares do conceito de inimigo: iniciando-se com o bárbaro, passando pelo pagão e herege até atingir o inumano, que pode e merece ser eliminado. Dentro dessa visão, o sistema político fica em choque com o sistema jurídico e se consegue assumir a primazia o resultado é a vulneração dos direitos fundamentais.

Ao Estado cabe o jus belli, ou seja, determinar o inimigo em virtude de uma decisão própria e combatê-lo (SCHMITT, 2020, p.83). Decerto que se o inimigo ultrapassa o limiar que o faz inumano, o recurso à violência física, no limite a própria guerra, se faz justificável para buscar a sua eliminação.

Essa referência ao Estado não afasta que, em qualquer âmbito, se o critério utilizado for amigo-inimigo, a decisão é política, seja numa organização, seja numa Igreja. Chama atenção o fato de Carl Schmitt dizer que os conceitos de amigo e inimigo não devem ser

\footnotetext{
${ }^{5}$ Que será trabalhada no item seguinte.
} 
tomados meramente como metáforas, mas no sentido existencial, e nesse sentido o inimigo não é apenas o concorrente (na esfera econômica) ou o opositor (na esfera ética, das discussões) (SCHMITT, 2020, p. 54). A forma amigo-inimigo é uma forma criada a partir do lado inimigo ${ }^{6}$. Como toda operação dessa lógica, o cruzamento para o lado oposto, para o lado amigo, consome tempo e vem a partir da homogeneização, ou seja, da integração aos valores, ritos e costumes que conformam a unidade de um povo.

Pode-se assim perguntar se o discurso político atual poderia realmente se enquadrar dentro da teoria schmittiana, isto é, se quando o Brasil repercute o discurso americano antichinês, por exemplo, se ele estaria realmente acreditando na necessidade de combater a China, como quando entram questões econômicas a respeito do $5 \mathrm{G}$ ou a respeito da cooperação para criação de uma vacina. A pergunta é pertinente pois é duvidoso que o governo brasileiro pense em um conflito real, em uma guerra contra a China.

Um exemplo real, no sentido existencial, é dado pela história brasileira do período da ditadura militar, de definição no âmbito interno de um inimigo. Os desaparecidos políticos dessa época indicam que a declaração de inimizade implicava a eliminação desse outro, desse estranho. Trata-se de um momento histórico sujeito a muitas tentativas de reescrita. Como na distopia de Orwell, onde o Ministério da Verdade cuidava de reescrever constantemente a história, há polêmicas recentes, como a ocorrida entre o Presidente da República e o Presidente da $\mathrm{OAB}$ a respeito da morte do pai desse último durante o regime militar. As comissões da verdade, a Lei da Anistia e as polêmicas recentes remetem a um tempo onde o discurso do inimigo e as ações para combate dos subversivos se uniam. Hoje, parece haver apenas o discurso e é preciso atenção para que o discurso não se convole em ação.

Esse é o quadro que combina a teoria schmittiana com a teoria dos sistemas no âmbito do sistema político. É preciso atentar para quais implicações isso pode ter para o sistema jurídico e para as cidadãs e os cidadãos.

\section{ORDENS AUTÁRQUICAS E ORDENS DEMOCRÁTICAS}

Um enquadramento do momento atual pode ser buscado nas linhas iniciais de Berman (2018) que destacam:

\footnotetext{
${ }^{6}$ Ver Brown (1972).
} 
We are living in dark, dark times. In Europe and the United States, the institutions of interlocking governance and democratic coexistence that have been carefully nurtured since 1945 are under attack. Nationalism, tribalism, xenophobia, and racism are fueling right-wing populist revolts against this legal order despite the fact that the period since 1945 has seen rises in health, longevity, prosperity, and peace that are perhaps unparalleled in human history.

Nacionalismo, tribalismo, xenofobia e racismo alimentam os ataques à ordem jurídica. A versão brasileira dessa onda vem com exaltação das cores nacionais e o abuso da palavra patriota. No Brasil a ordem jurídica foi colocada sob suspeita de contribuir para a decadência da nação causando uma polarização de dois lados irrazoáveis. E assim, o discurso do inimigo, daquele que deve ser combatido, eliminado, metralhado, assume o primeiro plano.

O mundo ajustado na ótica amigo-inimigo remete ao sonho de pureza, do desejo de ordem de que fala Bauman (1997, local. 171) onde cada coisa deve ocupar o seu lugar. Em dado momento o autor reflete que:

\footnotetext{
There are, however, things for which the 'right place' has not been reserved in any fragment of man-made order. They are 'out of place' everywhere; that is, in all places for which the model of purity has been designed. The world of the purityseekers is simply too small to accommodate them. It won't be enough to move them to another place; one needs to get rid of them once and for all - to burn them out, poison them, shatter them in pieces, put them to the sword.
}

O exemplo trágico de algo sem lugar possível é o povo judeu no mundo nazista. Nesse mundo apequenado por um ideal de ordem, a criação do ordenamento procura o desfazimento do diferente, daquele que em certo momento era marcado para a aniquilação (BAUMAN, 1997, local. 705) mas que em dado momento pareceu conquistar o direito de permanecer.

A tese de Neumann, do Direito como uma faca de dois gumes (NEUMANN, 2013, p. 40), é uma chave para a compreensão das disputas pelos direitos. Permite entender que a mudança e a transformação do Direito não necessitam sempre vir através de reformas, da proposta de mudança ou ruptura radical com o sistema (RODRIGUEZ, 2019, p. 72), não é necessário e nem viável desprezar as instituições, inclusive para modificar o sistema.

Um uso abusivo dessa tática está em curso. A política tributária da fórmula amigoinimigo usa do sistema constitucional para subvertê-lo. Demonstrações não faltam, como o paradoxo de atacar a imprensa livre e alegar o direito de liberdade de expressão; ou defender o AI-5 e ao mesmo tempo reclamar direitos constitucionais. 
Ao final, o Direito democrático acaba sendo utilizado para a composição de um direito autoritário, essa é a pretensão. "O sonho do poder autárquico é suprimir a sociedade ou qualquer outro entrave que impeça seu livre exercício" (RODRIGUEZ, 2019, p.75). E a constituição no sentido do constitucionalismo ${ }^{7}$, como acoplamento entre os sistemas diferenciados da política e do direito corre o risco de desaparecer se ocorrer a desdiferenciação do sistema jurídico subjugado pelo político.

A política baseada na distinção amigo-inimigo tem subjacente um poder que se pretende autárquico, no sentido de estar imune ao direito, de fugir do direito como define Rodriguez, e que se possível buscará se legitimar através da reserva de espaços de autarquia. Afinal, demandas de grupos diferentes geram instabilidade ao status quo, e o poder autárquico luta contra isso.

O inimigo, o diferente, o outro ou o estrangeiro, precisam ser integrados para o franqueamento à cidadania e aos direitos. A integração é uma violência, uma tentativa de supressão da diferença. Rodriguez (2019), Baseado em Young, aponta que a política moderna é dominada pela "lógica da identidade", uma identidade baseada ao final no homem branco europeu (MEISSNER; HEIL, 2020), que provoca muitas exclusões.

Houve um momento, lembra Habermas (2002, p. 134), em que a unidade de um povo mais ou menos homogêneo comportava a acomodação cultural da cidadania jurídica bem definida, mas nas sociedades pluralistas atuais cada vez mais se está afastado de um modelo de Estado nacional com população homogênea. "Não há qualquer alternativa a isso, a não ser que se pague o preço normativamente insuportável de purificações étnicas" (HABERMAS, 2002, p. 134). O desafio é encontrar uma alternativa que permita suportar a diferença, sem que seja preciso etiquetar o outro como algo sem lugar no mundo.

A integração é uma solução enganosa na opinião de Heil e Meissner (2020) e em seu lugar propõe-se o conceito de desintegração amistosa, que significa engajamento na diferença. Para os autores, enquanto a integração reproduz a assimetria de poder e impõe um fardo pesado aos imigrantes não brancos, a desintegração favorece a superdiversidade e aumenta a consciência das complicadas posições relativas nas sociedades multiculturais.

O conceito de Heil foi cunhado em vista da questão migratória, onde a retórica concernente à conter e restringir os migrantes tornou-se regular, onde o migrante é retratado

\footnotetext{
${ }^{7}$ Ver (NEVES, 2009), sobre a noção moderna de constituição e a respeito da construção de pontes de transição entre a racionalidade própria da política (democracia) e a do direito (o princípio da igualdade).
} 
como tendo de ser eliminado ou subjugado (MEISSNER; HEIL, 2020). Mas ele pode ser ampliado para abarcar além dos migrantes, os grupos vulneráveis, que têm sofrido com o backlash contra o multiculturalismo. Para abarcar todos aqueles que aparecem como “inimigos" no sentido schmittiano, e que devem por tal razão ser eliminados.

Essa questão tornou-se premente porque nunca o discurso do inimigo foi tão claro e contundente, no Brasil, como agora. Não existe nenhum pudor em aparecer na arena pública e fazer declarações, que soariam como criminosas até há pouco tempo. Schmitt, como explica Franco de Sá na apresentação de O Conceito do Político (SCHMITT, 2020), entende a política como um fenômeno essencialmente humano, baseado na possibilidade de conflito. A atualidade dessa teoria é sintoma de retrocesso das conquistas havidas desde o final da $2^{\text {a }}$ Guerra, momento em que a distinção da forma amigo-inimigo apareceu em toda sua crueza.

O código do sistema político pode ser encontrado a partir de diferentes distinções, como a democrática distinção governo-oposição, poder/ não poder, progressista/conservador e a autoritária amigo-inimigo. Fora da distinção política governo-oposição a tendência é o autoritarismo. A forma amigo-inimigo tornou-se a fórmula corrente das posições radicais no Brasil.

Portanto, a política entra em colisão com a ordem brasileira constitucionaldemocrática. A relação da Política e Direito envolvidos em tensão levanta a pergunta de como a tensão irá se resolver, se com a reação da ordem normativa sobre a política, contendo os arroubos autoritários, ou com a expansão de espaços autárquicos que arriscam ultrapassar o espectro democrático. Os dois movimentos são possíveis, de modo que o pluralismo jurídico, consequência da diversidade pode perder espaço, e assim, não resta aos que são diferentes, senão a integração, ou assumir o risco de serem capitulados como inimigos, não existe opção de engajamento na diferença, para a desintegração amistosa dentro do conceito político de Schmitt.

\section{CONCLUSÃO}

O presente trabalho propôs uma leitura sistêmico-autopoiética de O Conceito do Político de Carl Schmitt, buscando conectar as consequências dessa visão política para o Estado de Direito Democrático. Argumenta-se que um conceito baseado no código amigoinimigo tem como correlato jurídico um direito antidemocrático. Assim, a formação de zonas 
de autarquia, no sentido de Rodriguez, torna-se inevitável, caso persista o descompasso no tempo entre um sistema político autoritário e um direito democrático.

Schmitt trabalha a composição do conceito de maneira rigorosa. A resultante schmittiana do político, contudo, é autoritária. A distinção amigo-inimigo evoluiu, desde meados do século passado pelo menos, para distinção governo-oposição. Mas a situação da política nas duas últimas décadas revelou que essa visão de mundo construída nunca foi totalmente erradicada. Além de conseguir persistir ela se expandiu para além de grupos radicais, e agora ela ocupa espaços centrais de poder institucionalizado. Pode-se querer acreditar que esse discurso do inimigo é mera forma de expressão. Não obstante é bom lembrar que o inimigo deve ser combatido não apenas figurativamente, mas existencialmente.

Nesse viés, conclui-se que manifestações, como as do dia 7 de setembro, embora pacíficas na execução, contém em seu discurso e em suas reivindicações, traços totalitários e antidemocráticos, na medida em que fazem apologia ao período ditatorial, pedem o impeachment de Ministros da Suprema Corte brasileira, recrudescem o discurso da intervenção militar e carregam o anseio de que o presidente rompa com o diálogo democrático entre as instituições e passe a não mais respeitar as decisões do STF, tal como constata-se do próprio discurso do Presidente Jair Bolsonaro no dia do evento.

No mesmo sentido, embasado em Levitsky e Ziblatt, os discursos podem ser vistos de uma maneira subversiva pois não contêm traços de comunicação democrática. Eles tentam desguarnecer as instituições, deslegitimar o Direito na ameaça ao descumprimento das decisões jurídicas, e fazer predominar a lógica da política do amigo-inimigo, tal como demonstrado na teoria de Carl Schmitt.

Portanto, comunica-se uma pretensão por meio de uma roupagem democrática, que prega a liberdade de expressão, e o cumprimento da constituição e do dever de ordem, mas o que se transmite e se pode compreender resulta no oposto, o fim da liberdade de expressão e a destruição da ordem constitucional, resultando num fechamento operativo comunicacional do sistema da política para com os demais sistemas, com a criação de uma zona de autarquia onde a política tenta adquirir o primado sobre os demais sistemas, em especial, sobre o sistema jurídico.

Deve-se sempre ressaltar que a liberdade de expressão, como qualquer outro direito, não possui um caráter absoluto, tal como diversas vezes manifestado pela Suprema Corte 
brasileira nos casos em que o tema foi invocado para legitimar o direito de expressão do cidadão que atenta contra o Estado Democrático de Direito.

Foi visto também, que sem espaço no mundo político para a pluralidade e dada a relação estável existente entre o Direito e a Política, a tendência de abertura do Direito para a diferença e o pluralismo começa a ruir. Berman destacou o retorno da xenofobia no contexto americano e europeu, a ordem jurídica configura-se espaço de autarquia. Foi visto que, no limite, tratar o outro como inimigo cria uma situação cujo preço é demasiado alto. De mais a mais, e isso está presente em Bauman, não se deve acreditar que inexiste lugar próprio para a existência do diferente, pois isso bastaria para que se perseguisse a sua aniquilação.

Em síntese, o que se propõe é o contraste seguinte. A teoria dos sistemas assinala ao sistema político o código binário governo-oposição, o qual opera na modernidade no contexto dos Estados Democráticos de Direito. O conceito de Carl Schmitt, da forma inimigo, faz a democracia operar nos seus limites, na zona cinzenta entre democracia e autarquia, mas o seu campo próprio é fora do espectro democrático. Em outras palavras, a forma inimigo quando trazida para dentro da democracia por meio do discurso antidemocrático desloca perigosamente o Estado de Direito para a fronteira do Estado Totalitário, com o enfraquecimento das instituições e com o aumento da tensão entre o "nós", ou seja, a nação, e os "outros", ou seja, todos aqueles que não pactuam com o programa político pregado e praticado pelo governo.

Talvez seja possível levantar a hipótese, a ser analisada e verificada em outro contexto, de que o código da política não é fixo. Neste estudo viu-se duas possibilidades que parecem se alternar. Em contextos bélicos ou quando o Estado começa a dar demonstrações de autoritarismo, a operação do sistema político se baseia na forma amigo-inimigo. Em contextos democráticos o código governo-oposição é que opera.

Embora seja uma teoria inadequada para a ordem jurídica democrática e para o pluralismo jurídico, e seja uma teorização de uma realidade indesejável, a teoria de Schmitt possui valor reflexivo fundamental para a descrição da onda nebulosa e indeterminada que envolveu grande parte dos Estados e dos discursos políticos mais recentes no País.

Prestar atenção na sua análise política e nas consequências que lhe são inerentes tem potencial para fazer com que não se ignore os riscos e perigos, nem que se tenham como certas as conquistas evolutivas do Direito. 
A despeito desta questão, observa-se que a produção de dissenso é uma realidade da sociedade diferenciada funcionalmente e os movimentos de observação serão aqueles que apontam problemas e sugerem soluções. Não é possível prever o que vai acontecer no futuro, mas podemos afiar nossas ferramentas analíticas para estudar esses eventos quando de fato ocorrerem, pois, as comunicações estratégicas entre movimentos sociais, processos judiciais, mídia, governos e seus alvos não parecem ter seus dias findados no Brasil, pelo menos em curto prazo.

\section{REFERÊNCIAS BIBLIOGRÁFICAS}

BAUMAN, Zygmunt. Postmodernity and its Discontents. Cambrigde: Polity Press, 1997.

BERMAN, Paul Schiff. Global Legal Pluralism as a Normative Project. UC Irvine L. Review SSRN Electronic Journal, [s. l.], v. 149, 2018. Disponível em: https://doi.org/10.2139/ssrn.3288690.

BROWN, George Spencer. Laws of form. New York: The Julian Press, Inc, 1972.

HABERMAS, Jurgen. A inclusao do outro: estudos de teoria política. São Paulo: Edições Loyola, 2002.

KOSELLECK, Reinhart. Tradutor Markus Hediger. Histórias de Conceitos: Estudos sobre a semântica e a pragmática da linguagem política e social. Rio de Janeiro: CONTRAPONTO, 2020.

LEVITSKY, Steven; ZIBLATT, Daniel. Como as democracias morrem. Tradução de Renato Aguiar. Rio de Janeiro: Zahar, 2018.

LUHMANN, NIKLAS; TRANSLATED BY HOWARD DAVIES, John Raffan and Kathryn Rooney. Trust and power. 2nd. ed. Cambrigde: Polity Press, 2017.

LUHMANN., Niklas; Translated by John Bednarz Jr. Ecological Communication. Chicago; Cambridge: Polity Press; The University of Chicago Press, 1989.

LUHMANN, Niklas. Tradução de Javier Torres Nafarrate. Brunhilde Erker. Silvia Pappe e Luis Felipe Segura. El Derecho de la Sociedad. México DC: Universidad Iberoamericana e Herder Editorial, 2005.

MEISSNER, Fran; HEIL, Tilmann. Deromanticising integration: On the importance of convivial disintegration. Migration Studies, [s. l.], v. 0, n. 0, p. 1-19, 2020. Disponível em: https://doi.org/10.1093/migration/mnz056. 
NEUMANN, Franz. o IMPÉRIO DO DIREITO. São Paulo: Quartier Latin do Brasil, 2013.

NEVES, Marcelo. Transconstitucionalismo. São Paulo: Editora WMF Matins Fontes, 2009.

ROCHA, Leonel Severo. Da epistemologia normativista ao construtivismo sistêmico II. In: INTRODUÇÃO À TEORIA DO SISTEMA AUTOPOIÉTICO DO DIREITO. $2^{\mathrm{a}} \mathrm{ed}$. Porto Alegre: Livraria do Advogado Editora, 2013.

ROCHA, Leonel Severo. A verdade sobre a autopoiese do Direito/ Leonel Severo Rocha, Michael King, Germano Schwartz. Porto Alegre: Livraria do Advogado Editora, 2009.

RODRIGUEZ, José Rodrigo. A fuga do direito: um estudo sobre o direito contemporâneo. São Paulo: Saraiva, 2009.

RODRIGUEZ, José Rodrigo. Direito das Lutas. 1ªed. São Paulo: Liber Ars, 2019.

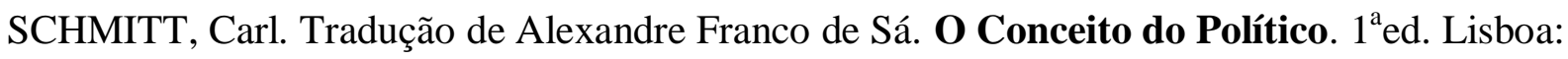
Edições 70, 2020.

THORNHILL, Chris. Crise democrática e direito constitucional global. Tradução de Diógenes Moura Breda e Glenda Vicenzi. São Paulo: Contracorrente, 2021. 